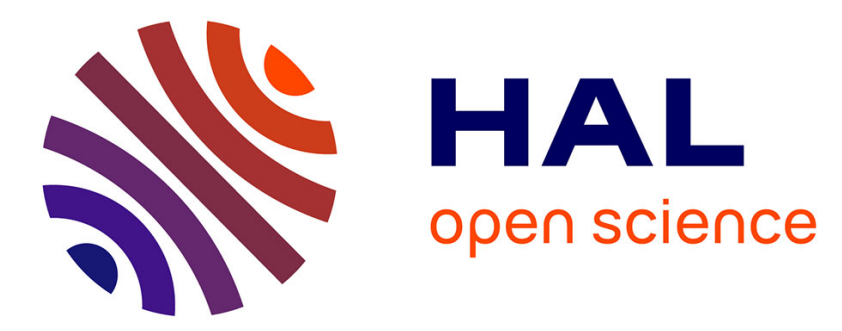

\title{
Development and in vitro evaluation of a novel lipid nanocapsule formulation of etoposide.
}

Benjamin Saliou, Olivier Thomas, Nolwenn Lautram, Anne Clavreul, José Hureaux, Thierry Urban, Jean-Pierre Benoit, Frédéric Lagarce

\section{- To cite this version:}

Benjamin Saliou, Olivier Thomas, Nolwenn Lautram, Anne Clavreul, José Hureaux, et al.. Development and in vitro evaluation of a novel lipid nanocapsule formulation of etoposide.. European Journal of Pharmaceutical Sciences, 2013, 50, pp.172-80. 10.1016/j.ejps.2013.06.013 • hal-03171789

\section{HAL Id: hal-03171789 \\ https://univ-angers.hal.science/hal-03171789}

Submitted on 17 Mar 2021

HAL is a multi-disciplinary open access archive for the deposit and dissemination of scientific research documents, whether they are published or not. The documents may come from teaching and research institutions in France or abroad, or from public or private research centers.
L'archive ouverte pluridisciplinaire HAL, est destinée au dépôt et à la diffusion de documents scientifiques de niveau recherche, publiés ou non, émanant des établissements d'enseignement et de recherche français ou étrangers, des laboratoires publics ou privés. 


\title{
Development and in vitro evaluation of a novel lipid nanocapsule formulation of etoposide
}

\author{
Benjamin Saliou $^{\mathrm{a}, 1}$, Olivier Thomas ${ }^{\mathrm{a}, 1}$, Nolwenn Lautram ${ }^{\mathrm{a}}$, Anne Clavreul ${ }^{\mathrm{a}, \mathrm{b}}$, José Hureaux ${ }^{\mathrm{a}, \mathrm{c}, \mathrm{d}}$, \\ Thierry Urban $^{\mathrm{a}, \mathrm{c}, \mathrm{d}}$, Jean-Pierre Benoit ${ }^{\mathrm{a}, \mathrm{e}}$, Frederic Lagarce ${ }^{\mathrm{a}, \mathrm{e}, *}$ \\ a Lunam Université, INSERM U1066, Micro et Nanomédecines Biomimétiques (MINT), Angers, France \\ ${ }^{\mathrm{b}}$ Neurosurgery Department, Academic Hospital, Angers, France \\ ' Pulmonology Department, Academic Hospital, Angers, France \\ ${ }^{\mathrm{d}}$ Equipe PYVER, University of Angers, Angers, France \\ e Pharmacy Department, Academic Hospital, Angers, France
}

\section{A R T I C L E I N F O}

\section{Article history:}

Received 2 April 2013

Received in revised form 11 June 2013

Accepted 25 June 2013

Available online 4 July 2013

\section{Keywords:}

Lipid nanocapsules

Etoposide

Scale-up

Cancer

Chemotherapy

Nanomedicine

\begin{abstract}
A B S T R A C T
Small cell lung cancer (SCLC) is the most aggressive carcinoma in thoracic oncology, unfortunately, despite chemotherapy, relapse is constant. The effect of etoposide, a major drug used against SCLC, can potentially be enhanced after its encapsulation in nanocarriers. The aim of this study was to use the technology of lipid nanocapsules (LNCs) to obtain nanocarriers with drug loadings compatible with clinical use and with an industrial process. Solubility studies with different co-solvent were first performed, then several process were developed to obtain LNCs. LNCs were then characterized (size, zeta potential, and drug loading). The best formulation called $\Omega$-LNCs had a size of $54.1 \pm 2.0 \mathrm{~nm}$ and a zeta potential of $-5.8 \pm 3.5 \mathrm{mV}$ and a etoposide drug loading of $5.7 \pm 0.3 \mathrm{mg} / \mathrm{g}$. The characteristics of this formulation were maintained after freeze drying and after a $15 \times$ scale-up. Release studies in a media mimicking plasma composition showed that $40 \%$ of the drug was released from the LNCs after $48 \mathrm{~h}$. Moreover the activity of etoposide after encapsulation was enhanced on H209 cells, IC50 was $100 \mu \mathrm{M}$ and $2.5 \mu \mathrm{M}$ for etoposide and etoposide LNCs respectively. Unfortunately the formulation failed to be more cytotoxic than etoposide alone on H69AR cells that are resistant to etoposide. This study showed that is was possible to obtain a new etoposide nanocarrier without the use of organic solvent, that the process is suitable for scale-up and freeze drying and finally that etoposide activity is maintained which is very promising for future treatment of SCLC.
\end{abstract}

(C) 2013 Elsevier B.V. All rights reserved.

\section{Introduction}

Small cell lung cancer (SCLC) is the most aggressive carcinoma in thoracic oncology (van Meerbeeck et al., 2011). Because of the short doubling time and high intrinsic spreading capacity of this cancer, nearly all patients have metastatic disease at diagnosis explaining why chemotherapy is the main therapy. Although a high chemosensibility in chemo naïve patients, relapse is constant.

Etoposide (4'-demethyl-epipodophyllotoxin) remains one of the pivotal drug against SCLC (Hainsworth and Greco, 1995; You et al., 2008). The action of this molecule is to inhibit human topoisomerase II which leads to apoptosis of tumor cells (Beauchesne et al., 1999). In its commercial form, it can be combined with alcohol, and surfactant like polysorbate 80 or Cremophor EL (polyethoxy-

\footnotetext{
* Corresponding author. Address: Inserm U1066, Bâtiment IRIS, CHU Angers, 4 rue Larrey, 49033 Angers, France. Tel.: +33 24468 8545; fax: +33 244688546 .

E-mail address: frederic.lagarce@univ-angers.fr (F. Lagarce).

1 These authors contributed equally to this work.
}

lated castor oil) and diluted in physiological salt solution. These additives display cell toxicity and modify the pharmacokinetics of the drug (Ellis et al., 1996; Jelinek and Klocking, 1998). Two formulations of etoposide are currently used: capsules for oral administration and solution for intravenous administration. Encapsulation of the drug in colloidal carriers could allow a higher concentration of etoposide in primary tumor and metastatis due to the enhanced retention and permeation (EPR) effect and theoretically improve safety and efficiency of the drug (Huynh et al., 2010).

Up to now, different nanoparticles containing etoposide were formulated mainly in polymeric nanospheres (Callewaert et al., 2012; Gaucher et al., 2007; Kilicay et al., 2011; Poreba et al., 2011; Yadav et al., 2011) or solid lipid nanoparticles (Khajavinia et al., 2012; Patlolla and Vobalaboina, 2008; Reddy et al., 2006; Zhang et al., 2011). Others nanoparticles such as liposomal formulations (Jinturkar et al., 2012), micelles (Mohanty et al., 2010; Varshosaz et al., 2012) or dendrimers (Sideratou et al., 2010) were also evaluated. Unfortunately, most of these particles has major drawbacks such as presence of organic solvent or toxic compounds 
preventing their exploitation in clinical use. On the contrary solvent free lipid nanocapsules (LNCs) have shown a very good toxicological profile after intravenous infusion and are produced only with GMO free and generally recognized as safe (GRAS) excipients (Hureaux et al., 2009, 2010).

The aim of this study was to develop solvent-free lipid nanocapsules able to entrap etoposide for human use. Then the LNCs formulated were characterized, the release was studied in a biomimetic environment and tested on NCI-H209 and H69AR, cell lines of SCLC sensible and resistant to etoposide (Hillgenberg et al., 1999; Mirski et al., 1987), respectively.

\section{Materials and methods}

\subsection{Materials}

Etoposide powder was purchased from Ascent Scientific (Bristol, Great-Britain). Oil solubilizers and excipients were provided by Gattefosse S.A. (Saint-Priest, France), or Abitec Corp. (Colombus, USA), or purchased from Sigma-Aldrich (Saint-Quentin Fallavier, France) or Fluka (Buchs, Switzerland). Lipoïd ${ }^{\circledR}$ S75-3 (soybean lecithin at $70 \%$ of phosphatidylcholine and $10 \%$ phospatidylethanolamine) and Solutol ${ }^{\circledR}$ HS15 (mixture of free polyethylene glycol 660 and polyethylene glycol 660 hydrostearate) were a gift from Lipoïd Gmbh (Ludwigshafen, Germany) and BASF (Ludwigshafen, Germany), respectively. $\mathrm{NaCl}$ was purchased from Prolabo VWR International (Fontenay-sous-Bois, France). Purified water was obtained from a MilliQ185 System (Millipore, Paris, France). Methanol HPLC grade was purchased from Fisher Scientific (Loughborough, Great-Britain). Reagents for activating complement test were purchased from Eurobio (Courtaboeuf, France), Merck (Fontenay-sous-Bois, France), Sigma-Aldrich, Fluka (Buchs, Switzerland) and the Etablissement Français du Sang (Nantes, France). Culture reagents were obtained from Lonza (Verviers, Belgium).

\subsection{Solubility studies}

In order to determine the oils or excipients which could solubilize etoposide, a screening study was performed. This task was accomplished by introducing $5 \mathrm{mg}$ of etoposide in different tubes containing $1 \mathrm{~g}$ of each oil or excipients. After $24 \mathrm{~h}$ at room temperature, tubes were observed visually in order to evaluate the etoposide solubility. Then, the samples were introduced in a water bath Julabo SW22 stirred at $125 \mathrm{rpm}$ during $24 \mathrm{~h}$ at $60^{\circ} \mathrm{C}$ and the etoposide solubility was again evaluated at this temperature. If the powder had visually disappeared, the minimum solubility of etoposide in the compound was considered to be $0.5 \%(\mathrm{w} / \mathrm{w})$.

The maximum solubility of etoposide in oil or excipient was finally determined by high performance liquid chromatography (HPLC), following an adaptation of a method previously described (Shirazi et al., 2001). The apparatus was composed by injector (Waters $^{\circledR}$ 717plus), pump (Waters ${ }^{\circledR} 660 \mathrm{E}$ ), detector (Waters ${ }^{\circledR}$ 2487), controller (Waters ${ }^{\circledR} 600$ ), software: Millenium 32 version 3.2 (Waters ${ }^{\circledR}$, Saint Quentin-en-Yvelines, France). The column used was a Sunfire ${ }^{\circledR} \mathrm{C} 185 \mu \mathrm{m} 4.6 * 150 \mathrm{~mm}$ from Waters ${ }^{\circledR}$. Injected volume and run time were respectively $20 \mu \mathrm{L}$ and $8 \mathrm{~min}$. The mobile phase was composed of $70 \%$ methanol plus $30 \%$ purified water, the flow rate was $1 \mathrm{~mL} / \mathrm{min}$ and the detection wavelength was $228 \mathrm{~nm}$. For this experiment, an excess of etoposide was introduced in hemolysis tubes. Then, the tubes were placed in a water bath Julabo SW22 at $60{ }^{\circ} \mathrm{C}$, stirred at $125 \mathrm{rpm}$ during $24 \mathrm{~h}$ and supernatant were then collected and filtered through Acrodisc ${ }^{\circledR}$ $13 \mathrm{~mm}$ filters from Pall Corporation ${ }^{\circledR}$ (Ann Arbor, USA). Finally, the filtrate was diluted 10,000 fold to obtain a concentration of eto- poside in the range where it was linear with respect to the area under the curve (between 0.25 and $12 \mu \mathrm{g} / \mathrm{mL}, R^{2}=0.999$, maximum deviation below $10 \%$ ).

\subsection{LNC formulation}

\subsubsection{LNC formulation without etoposide}

LNCs were obtained according to the patent filed by Heurtault et al. (2001) and based on the phase-inversion process (Heurtault et al., 2002). Indeed, the PEG-chains of the Solutol ${ }^{\circledR}$ HS15, which is one of the surfactant of the LNCs, dehydrate following an increase of temperature. This phenomenon leads to lowering the HLB balance and induce the phase inversion to water in oil emulsion from oil in water emulsion.

Based on results of the solubility study and works of Roger et al. (2011), a mixture of Labrafac ${ }^{\circledR}$ CC, Labrafil ${ }^{\circledR}$ M1944CS and Transcutol $^{\circledR} \mathrm{HP}(0.4 \mathrm{~g}, 0.12 \mathrm{~g}$, and $0.4 \mathrm{~g}$ respectively) was chosen as the oily phase. Then, these compounds were mixed with $150 \mathrm{mg}$ of Lipoïd ${ }^{\circledR}$ S75-3, and heated by an IKA RCT Classic hot plate at $82{ }^{\circ} \mathrm{C}$ with agitation to $1200 \mathrm{rpm}$ maintained until complete solubilization of this compound. Then, once the ambient temperature of the mixture was recovered, the other compounds of the formulation i.e., water, $\mathrm{NaCl}$ and Solutol HS15 ( $1.8 \mathrm{~g}, 0.1 \mathrm{~g}$, and $1 \mathrm{~g}$ respectively) were introduced. After that, the heating cycles were performed between 60 and $90^{\circ} \mathrm{C}$ with a gradient of $4^{\circ} \mathrm{C} / \mathrm{min}$ while the system was quenched at $70^{\circ} \mathrm{C}$ by adding $5 \mathrm{~mL}$ of $0{ }^{\circ} \mathrm{C}$ deionised water. Finally, the agitation of $1200 \mathrm{rpm}$ provided during every steps of formulation was maintained until the solution reached the room temperature.

\subsubsection{Formulation of LNCs loaded with etoposide}

In a first step, etoposide was solubilized in Transcutol ${ }^{\circledR}$ HP. Then, LNCs were synthesized with etoposide using two distinct ways. In the first way, oil solubilizing etoposide was placed in contact with other compounds and the heating cycles were performed (called Ref-LNCs further in text). In the second way, the heating cycles were operated with all compounds, except Transcutol ${ }^{\circledR} \mathrm{HP}$ and etoposide and then Transcutol ${ }^{\circledR}$ HP solubilizing etoposide was introduced at the beginning of the last cooling step as patented previously by our group (Benoit et al, 2010).

\subsubsection{Formulation of LNCs without Lipoïd ${ }^{\circledR}$ S75-3}

For the formulation of LNCs without Lipoïd ${ }^{\circledR}$ S75-3 (called $\Omega$ LNCs further in text), the percentage of each component of the oily core were kept the same but the mass had to be decreased in order to compensate the lack of this surfactant, and thus, keeping size of LNCs close to $50 \mathrm{~nm}$. So, the oily mix was composed by $0.3 \mathrm{~g}$ of Labrafac $^{\circledR}$ CC, $0.9 \mathrm{~g}$ of Labrafil ${ }^{\circledR}$ M1944CS and $0.3 \mathrm{~g}$ of Transcutol ${ }^{\circledR}$ HP.

\subsection{Characterization of LNCS}

LNC size distribution was measured by dynamic light scattering (DLS) and zeta potential values were assessed using a Zetasizer Nano ZS from Malvern (Orsay, France). The helium-neon laser, $4 \mathrm{~mW}$, operates at $663 \mathrm{~nm}$ with the scatter angle fixed at $173{ }^{\circ} \mathrm{C}$ and the temperature fixed at $25^{\circ} \mathrm{C}$. Measurements were performed three times for each experimental point. Size diameter corresponds to intensity of the signal.

\subsection{Determination of encapsulation efficiency and drug loading}

The encapsulation efficiency determination of the etoposide was carried out by HPLC, (same experimental conditions that are described above in text). LNCs were separated from supernatant using Nanosep ${ }^{\circledR}$ Omega $30 \mathrm{kD}$ microcentrifuge filters (Pall Corporation, Ann Arbor, USA) and etoposide was measured in the 
supernatant. The encapsulation efficiency was determined by dividing the experimental drug loading by the theoretical drug loading.

\subsection{Study of release}

The determination of the release kinetics of etoposide was studied $(n=3)$ in an artificial biomimetic environment. It consisted in placing dialysis tubes (which cut-off was $50 \mathrm{kD}$ ) containing $16 \mathrm{mg}$ of etoposide encapsulated in LNCs. Each tube was placed in $300 \mathrm{~mL}$ of aqueous medium containing $60 \mathrm{~g} / \mathrm{L}$ of bovine serum albumin (BSA), $9 \mathrm{~g} / \mathrm{L}$ of $\mathrm{NaCl}$ and buffered to $\mathrm{pH} 7.4$ with $\mathrm{NaOH}$ $1 \mathrm{~mol} / \mathrm{L}$. The beakers containing the dialysis tubes were then placed in a water bath at $37^{\circ} \mathrm{C}$ stirred at $50 \mathrm{rpm}$. Then, the continuous medium to the dialysis tubes was collected at $15,30,60,90$, $120,240,360 \mathrm{~min}, 18,24,45.5$ and $72 \mathrm{~h}$. In order to precipitate the protein and to determine the etoposide content, $200 \mu \mathrm{L}$ of the continuous medium were placed in $1800 \mu \mathrm{L}$ of methanol and were centrifuged at $10,000 \mathrm{rpm}$ for $10 \mathrm{~min}$. The supernatant was then assayed by HPLC (same experimental conditions that are described above in text but the linearity zone was between 0.4 and $8 \mu \mathrm{g} / \mathrm{mL}$, $R^{2}=0.999$, and the maximum deviation was always found below $20 \%)$.

\subsection{Hemolytic complement activation}

Hemolytic complement activation tests were performed according to a protocol adapted to nanoparticles and described previously (Vonarbourg et al., 2006). Briefly, the LNCs are associated with the complement proteins which become activated and lead to the destruction of erythrocytes. The absorbance determined with the Multiskan Ascent (Labsystems SA, Cergy-pontoise, France) was then correlated with the activation percentage.

\subsection{Cells experiments}

\subsubsection{Tumor cell culture}

SCLC lines H209 and H69AR were obtained from ATCC (LGC, Molsheim, France). The cells were cultured at $37^{\circ} \mathrm{C}$ in a humidified atmosphere containing $5 \% \mathrm{CO}_{2}$ in Roswell Park Memorial Institute medium (RPMI) with L-glutamine (Lonza) supplied with $20 \%$ foetal bovine serum (FBS), 1\% Na Pyruvate, HEPES $0.01 \mathrm{M}$ and $1 \%$ antibiotic and antimycotic solution (Sigma).

\subsubsection{In vitro cell viability}

H209 or H69AR cells were first plated at $4.10^{4}$ cells $/ \mathrm{cm}^{2}$ on 96 well plates for $48 \mathrm{~h}$ in RPMI containing $10 \%$ FBS, $1 \%$ Na Pyruvate, HEPES $0.01 \mathrm{M}$ and $1 \%$ antibiotic/antimitotic and then treated with increasing concentrations of various etoposide preparations (0.01$100 \mu \mathrm{mol} / \mathrm{L}$ ). To test the impact of the drug alone (non-encapsulated) on cells, methanol was used to solubilize the drug. The drug in solution was prepared at a concentration of $0.1 \mathrm{M}$ and a dilution of 1:1000 in culture medium was realized to obtain the higher concentration tested on cells $(100 \mu \mathrm{mol} / \mathrm{L})$. Blank LNCs were tested as controls and with the same excipient concentration than that needed for etoposide ones. The cells were incubated at $37{ }^{\circ} \mathrm{C} / 5 \%$ $\mathrm{CO}_{2}$ for $72 \mathrm{~h}$. Cell viability was determined by CyQUANT ${ }^{\circledR}$ Cell Proliferation assay (Invitrogen, Carlsbad, CA), following the manufacturer's instructions. Briefly, $200 \mu \mathrm{L}$ of cell-lysis buffer solution diluted 20-fold in distilled water and including CyQUANT ${ }^{\circledR}$ (diluted 400 -fold into the $1 \times$ cell-lysis buffer) was added to each well, and the plates were incubated at room temperature for $5 \mathrm{~min}$, protected from light.

Then, $100 \mu \mathrm{L}$ of each sample was transferred into a microplate and the fluorescence was determined using $485 \mathrm{~nm}$ for the excitation and $515 \mathrm{~nm}$ for the emission wavelengths using a multiwell- scanning spectrophotometer Fluoroscan Ascent FL (Labsystems SA, Cergy-pontoise, France). Three independent repetition experiments were conducted, each with at least 3 repeated samples.

\subsection{Freeze-drying of etoposide free LNCS}

The storage test of etoposide free LNCs were carried out by freeze-drying with a freeze-dryer Lyovac Steris GT2 (Steris, Germany), to a pump 2005 C1 from Alcatel (Annecy, France) and a cryostat CC 505 from Huber (Barr, France).

The LNCs were freeze-dried in the presence and absence of trehalose, as cryoprotectant. When a cryoprotectant was added, the mass of trehalose was equal to the mass of dry LNCs. In each case, the mass of freeze-dried solution was $1.5 \mathrm{~g}$.

\subsection{Scale-up assay}

The scale-up of LNCs was performed on the formulation whose characteristics seem to fit the problems of the subject. The weight of all compounds was multiplied by 15 -fold.

\subsection{Statistics}

Results were expressed as mean values \pm SD. A Student's $t$-test was used for statistical comparison/analysis. $P<0.05$ was considered statistically significant.

\section{Results}

\subsection{Solubility studies}

Several oily excipients were evaluated at $0.5 \% \mathrm{w} / \mathrm{w}$ concentration to room temperature and $60{ }^{\circ} \mathrm{C}$. Among the 27 oils or excipients tested, only nine have concluded to a solubility of etoposide due to a partial or complete disappearance of the powder initially introduced. The results of this experiment are recorded in Table 1.

The maximum solubility of etoposide has been determined by HPLC for Transcutol ${ }^{\circledR} \mathrm{HP}(74.85 \mathrm{mg} / \mathrm{mL})$, Tween ${ }^{\circledR} 80(39.12 \mathrm{mg} / \mathrm{mL})$, Capmul $^{\circledR} 907 \mathrm{P}(8.961 \mathrm{mg} / \mathrm{mL})$ and Labrafac $^{\circledR} \mathrm{CC}(0.074 \mathrm{mg} / \mathrm{mL})$.

Among the oily excipients evaluated, Transcutol $\mathrm{HP}^{\circledR}$ showed the better etoposide solubility. Moreover, it was the only product able to solubilize etoposide at room temperature.

\subsection{Formulation of $L N C S$}

In order to obtain a nanocapsule diameter close to $50 \mathrm{~nm}$ with a PDI inferior to 0.2 , the oily core of the nanocapsules was composed by $20 \%$ Labrafac $^{\circledR}$ CC, 60\% Labrafil ${ }^{\circledR}$ M1944CS and 20\% Transcutol $^{\circledR}$ HP. These conditions allowed the encapsulation of etoposide with a medium and variable encapsulation efficiency (Table 2).

\subsection{Optimization of formulation}

\subsubsection{Composition of the oily core}

Transcutol ${ }^{\circledR}$ HP was the only component of the oily core able to solubilize etoposide. It was thus sought to increase its percentage in the lipid nanocapsules. Several formulations of LNC without etoposide have been performed, characterized in terms of stability, size diameter and polydispersity index. A ternary diagram was built with the three components (Labrafac ${ }^{\circledR} \mathrm{CC}$, Labrafil ${ }^{\circledR}$ M1944CS and Transcutol ${ }^{\circledR}$ HP) of the oily core (Fig. 1).

The ternary diagram showed a zone delimited by green dots where stable LNCs could be obtained (size stable along 7 days and PDI remained $<0.2$ ). In this area, the percentage of transcutol ${ }^{\circledR}$ $\mathrm{HP}$ in the core of LNCs could be doubled. Unfortunately, a 
Table 1

Solubility of etoposide in different oils or excipients, S: solubility observed, NS: no solubility observed.

\begin{tabular}{|c|c|c|}
\hline Oil solubilizers or excipients & $\begin{array}{l}\text { Solubility at room } \\
\text { temperature }\end{array}$ & $\begin{array}{l}\text { Solubility at } \\
60^{\circ} \mathrm{C}\end{array}$ \\
\hline Capmul 907P & NS & $\mathrm{S}$ \\
\hline Capmul MCM-EP ${ }^{\circledR}$ & NS & $\mathrm{S}$ \\
\hline Capmul GMO-50 & NS & $\mathrm{S}$ \\
\hline Captex 200P ${ }^{\circledR}$ & NS & NS \\
\hline Captex $225^{\circledR}$ & NS & NS \\
\hline Captex $350^{\circledR}$ & NS & NS \\
\hline Captex GTO ${ }^{\circledR}$ & NS & NS \\
\hline Captex $300^{\circledR}$ & NS & NS \\
\hline Castor oil & NS & NS \\
\hline Coconut oil & NS & NS \\
\hline Cod liver oil & NS & NS \\
\hline Corn oil & NS & NS \\
\hline Ethyl oleate & NS & NS \\
\hline Labrafac CC $\left.{ }^{(}\right)$ & NS & S \\
\hline $\begin{array}{l}\text { Labrafac } \mathrm{CC}^{\circledR}+2 \%(\mathrm{w} / \mathrm{w}) \\
\quad \text { cholesterol }\end{array}$ & NS & NS \\
\hline Labrafil M1944 CS ${ }^{\circledR}$ & NS & NS \\
\hline Laurygol $90^{\circledR}$ & NS & S \\
\hline Maisine $35-1^{\circledR}$ & NS & NS \\
\hline Oleic plurol & NS & NS \\
\hline Safflower oil & NS & NS \\
\hline Sesame oil & NS & NS \\
\hline Solutol HS15 $5^{\circledR}$ & NS & $S$ \\
\hline Span $80^{\circledR}$ & NS & NS \\
\hline Transcutol HP ${ }^{\circledR}$ & $\mathrm{S}$ & $\mathrm{S}$ \\
\hline Tween $80^{\circledR}$ & NS & $\mathrm{S}$ \\
\hline Vitamine $\mathrm{E}^{\circledR}$ & NS & NS \\
\hline Vitamine E TPGS ${ }^{\circledR}$ & NS & $\mathrm{S}$ \\
\hline
\end{tabular}

destabilization of the LNCs has been observed after encapsulation of etoposide when the core was composed of more than $20 \%$ Transcutol $^{\circledR}$ HP. The formulation with $40 \%$ of Transcutol ${ }^{\circledR}$ HP (S green dot - Fig. 1) even showed a total release of etoposide after 7 days (data not shown).

\subsubsection{Influence of Lipoïd ${ }^{\circledR}$ S75-3}

Lipoïd ${ }^{\circledR}$ S75-3, a soybean lecithin, acts as surfactant in the formulation but its solubilization is difficult and can explain difference in encapsulation results between batches. Thus, LNCs formulated in absence of this surfactant were evaluated (Table 3). If the percentage of each component of the oily core remained the same, their amount was decreased in order to obtain an identical diameter of the nanocapsules.

The drug loading slightly decreased in the formulation of LNCs without Lipoïd ${ }^{\circledR}$ S75-3, due to the decrease of Transcutol HP in the formulation, but the encapsulation efficiency was more reproducible and the polydispersity of LNCs was lower. The zeta potential increased. In the following study, LNCs with and without Lipoïd ${ }^{\circledR}$ S75-3 were studied jointly.

\subsubsection{Transcutol ${ }^{\circledR} H P$ addition}

As performed classically, the active molecule was introduced into the oily core prior to the completion of three heating cycles of the solution. However, an original modification of the LNC formulation (Benoit et al., 2010), allowed to introduce the drug just before the quenching. LNCs with or without Lipoïd ${ }^{\circledR}$ S75-3 were formulated to introduce Transcutol ${ }^{\circledR} \mathrm{HP}$ solubilizing etoposide at the beginning of cooling of the last heating (Table 4).

No major difference was observed between the formulation studied even if the addition of Transcutol ${ }^{\circledR}$ HP solubilizing etoposide during the last cooling has improved the encapsulation efficiency of etoposide for each of the formulation containing Lipoïd ${ }^{\circledR}$ S75-3 $(P<0.05)$.

\subsubsection{Freeze-drying study}

Before any clinical study, it will be necessary to assess the ability of LNCs loaded with etoposide to be lyophilized. Based on previous works (Dulieu and Bazile, 2005), freeze-drying tests was performed on formulations non-loaded with etoposide for safety reasons (Table 5) in the presence or absence of trehalose (as cryoprotectant). Two formulations with or without Lipoïd ${ }^{\circledR}$ S75-3 (called Ref and $\Omega$, respectively) were evaluated.

Freeze-drying of formulation with Lipoïd ${ }^{\circledR}$ S75-3 showed an increase of the LNCs diameter and polydispersity index, even in presence of trehalose as cryoprotectant. In contrast, nanoparticles formulated without Lipoid ${ }^{\circledR}$ S75-3 could be lyophilized without change of their initial characteristics. Based on this last result, only $\Omega$-type LNCs (i.e., without Lipoïd ${ }^{\circledR}$ S75-3) were studied in following

Table 2

Characterization of blank and etoposide loaded LNCs ( $n=3$ for each batch of LNCs).

\begin{tabular}{|c|c|c|c|c|c|}
\hline & Size $(\mathrm{nm})$ & PDI & Zeta potential (mV) & Encapsulation efficiency (\%) & Drug loading (mg/g) \\
\hline Blank LNCs & $46.8 \pm 2.9$ & $0.089 \pm 0.050$ & $-12.06 \pm 0.09$ & - & - \\
\hline Etoposide loaded LNCs & $49.2 \pm 4.1$ & $0.123 \pm 0.039$ & $-20.26 \pm 3.17$ & $56.7 \pm 21.3$ & $6.5 \pm 3.0$ \\
\hline
\end{tabular}

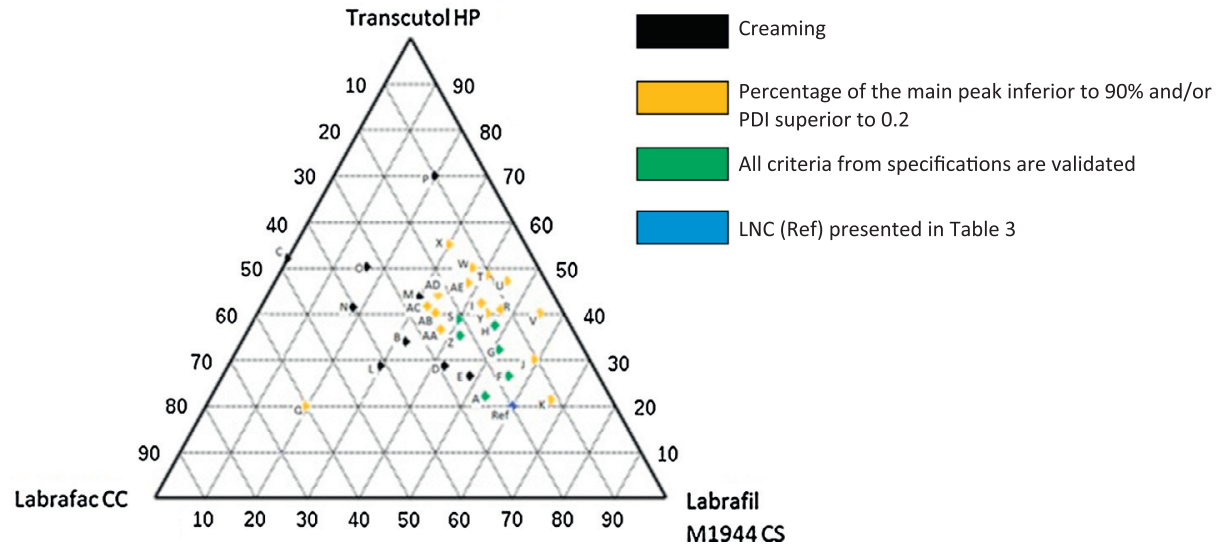

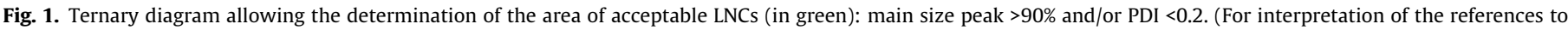
color in this figure legend, the reader is referred to the web version of this article.) 
Table 3

Characteristics of LNCs obtained with or without Lipoid ${ }^{\circledR}$ S75-3.

\begin{tabular}{|c|c|c|c|c|c|c|}
\hline & Lipoid S75-3 (mg) & Size $(\mathrm{nm})$ & PDI & Zeta potential $(\mathrm{mV})$ & Encapsulation efficiency (\%) & Drug loading $(\mathrm{mg} / \mathrm{g})$ \\
\hline LNC with lipoid & 14.8 & $49.2 \pm 4.1$ & $0.123 \pm 0.039$ & $-20.26 \pm 3.17$ & $56.7 \pm 21.3$ & $6.5 \pm 3.0$ \\
\hline LNC without lipoid & 0 & $52.7 \pm 0.2$ & $0.070 \pm 0.001$ & $-2.24 \pm 0.73$ & $77.9 \pm 2.5$ & $5.4 \pm 0.7$ \\
\hline
\end{tabular}

Table 4

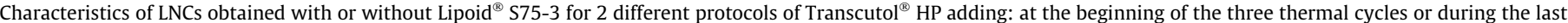
cooling step.

\begin{tabular}{|c|c|c|c|c|c|c|}
\hline & Transcutol ${ }^{\circledR}$ HP adding time & Size $(\mathrm{nm})$ & PDI & Zeta potential (mV) & Encapsulation efficiency (\%) & Drug loading $(\mathrm{mg} / \mathrm{g})$ \\
\hline \multirow[t]{2}{*}{ LNC with lipoid } & Beginning & $49.2 \pm 4.1$ & $0.123 \pm 0.039$ & $-20.26 \pm 3.17$ & $56.7 \pm 21.3$ & $6.5 \pm 3.0$ \\
\hline & Last cooling & $50.8 \pm 3.5$ & $0.140 \pm 0.057$ & $-16.62 \pm 2.01$ & $74.0 \pm 1.6$ & $5.8 \pm 0.8$ \\
\hline \multirow[t]{2}{*}{ LNC without lipoid } & Beginning & $52.7 \pm 0.2$ & $0.070 \pm 0.001$ & $-2.24 \pm 0.73$ & $77.9 \pm 2.5$ & $5.4 \pm 0.7$ \\
\hline & Last cooling & $54.1 \pm 2.0$ & $0.100 \pm 0.020$ & $-5.81 \pm 3.53$ & $75.8 \pm 3.3$ & $5.7 \pm 0.3$ \\
\hline
\end{tabular}

Table 5

Characteristics of LNCs obtained after different freeze drying conditions.

\begin{tabular}{|c|c|c|c|c|c|c|}
\hline \multirow{2}{*}{$\begin{array}{l}\text { Formulation } \\
\text { Status }\end{array}$} & \multicolumn{3}{|c|}{ With $14.8 \mathrm{mg}$ lipoid (Ref) } & \multicolumn{3}{|c|}{ Without lipoid $(\Omega)$} \\
\hline & $\begin{array}{l}\text { Before freeze } \\
\text { drying } \\
(n=3)\end{array}$ & $\begin{array}{l}\text { After freeze drying } \\
\text { with trehalose } \\
(n=1)\end{array}$ & $\begin{array}{l}\text { After free drying } \\
\text { without trehalose } \\
(n=1)\end{array}$ & $\begin{array}{l}\text { Before freeze } \\
\text { drying } \\
(n=3)\end{array}$ & $\begin{array}{l}\text { After freeze drying } \\
\text { with trehalose } \\
(n=3)\end{array}$ & $\begin{array}{l}\text { After free drying } \\
\text { without trehalose } \\
(n=3)\end{array}$ \\
\hline Size $(\mathrm{nm})$ & $46.8 \pm 2.9$ & 52.3 & 49.9 & $54.1 \pm 2.0$ & $53.9 \pm 3.1$ & $48.3 \pm 3.6$ \\
\hline Main peak (\%) & $99.6 \pm 0.7$ & 76.5 & 96.8 & $99.2 \pm 0.3$ & $98.6 \pm 1.2$ & $99.7 \pm 0.5$ \\
\hline PDI & $0.089 \pm 0.051$ & 0.263 & 0.228 & $0.100 \pm 0.020$ & $0.157 \pm 0.032$ & $0.122 \pm 0.042$ \\
\hline Zeta potential $(\mathrm{mV})$ & $-12.1 \pm 0.9$ & ND & ND & $-5.8 \pm 3.5$ & $-1.1 \pm 1.1$ & $-4.7 \pm 0.5$ \\
\hline
\end{tabular}

experiments.

\subsection{Characterization of $\Omega$-formulation}

\subsubsection{Stability study}

A stability study analyzing sizes and polydispersity index of loaded etoposide and blank $\Omega$-LNCs was performed over a period of 15 days at $4{ }^{\circ} \mathrm{C}$ temperature storage. The results of this study are presented in Fig. 2.

No change in size was observed over a period of 15 days for blank nanocapsules or etoposide loaded nanocapsules. The polydispersity index also remained lower than 0.1 .

\subsubsection{Hemolytic complement activation}

Hemolytic complement activation is an in vitro test leading to an in vivo projection of interactions between the LNCs and the human plasma. The study was performed on the $\Omega$-type LNCs loaded and non-loaded with etoposide. The results obtained (Fig. 3) were

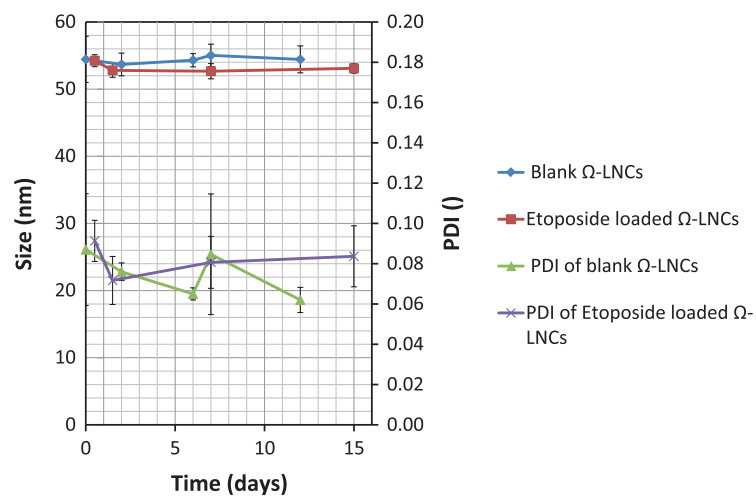

Fig. 2. Size and polydispersity index (PDI) of lipid nanocapsules ( $n=3$ batches for each formulation) loaded or non-loaded with etoposide along 15 days. compared with two other formulations which are the PMMA nanospheres and the LNCs made with Labrafac ${ }^{\circledR} \mathrm{CC}$ (Vonarbourg et al., 2006) known to be very activating and not activating, respectively.

Thanks to this result, it was possible to observe that the LNCs loaded with etoposide were not more complement activating than the non-loaded LNCs and they were both only slightly more activating than the LNCs made of Labrafac ${ }^{\circledR} \mathrm{CC}$.

\subsubsection{Release study}

The release of etoposide through a membrane of $50 \mathrm{kD}$ in a biomimetic environment was studied on three beakers for $72 \mathrm{~h}$. The media contained protein at a concentration close to that of plasma. The amount of $\Omega$-LNCs loaded with etoposide per unit volume was calculated to mimic the injection of a therapeutic dose $(150 \mathrm{mg} /$ $\mathrm{m}^{2}$ ). Thus, the release of etoposide was found closer to in vivo conditions in the plasma. The HPLC results of the continuous medium are presented in Fig. 4.

\subsection{In vitro cell viability}

The CyQUANT $^{\circledR}$ Cell Proliferation assay was used to determine in vitro cytotoxicity after exposure of $\Omega$-LNCs (with or without etoposide) to both cells lines H209 and H69AR with a cascade concentration range of etoposide $(0.01-100 \mu \mathrm{M})$. A short exposure time (72 h) was deliberately chosen to only observe the cytotoxicity activity of the LNC on cells (no impact of culture conditions on cell viability). The cell survival profiles of the H209 cells and H69AR cells exposed on etoposide-LNCs, blank-LNCs and free etoposide were illustrated in Figs. 5 and 6, respectively.

H209 cell culture studies revealed that at low concentrations (0.01-0.1 $\mu \mathrm{M}$ ), neither etoposide solution nor LNCs (blank or etoposide loaded) altered the cell growth. At $1 \mu \mathrm{M}$ concentration, the cell viability was decreased by the addition of etoposide loaded LNC and etoposide solution, while blank nanocapsules had no effect on it. At higher concentrations $(10-100 \mu \mathrm{M})$, cell survival was dramatically decreased for blank or etoposide loaded LNCs, 


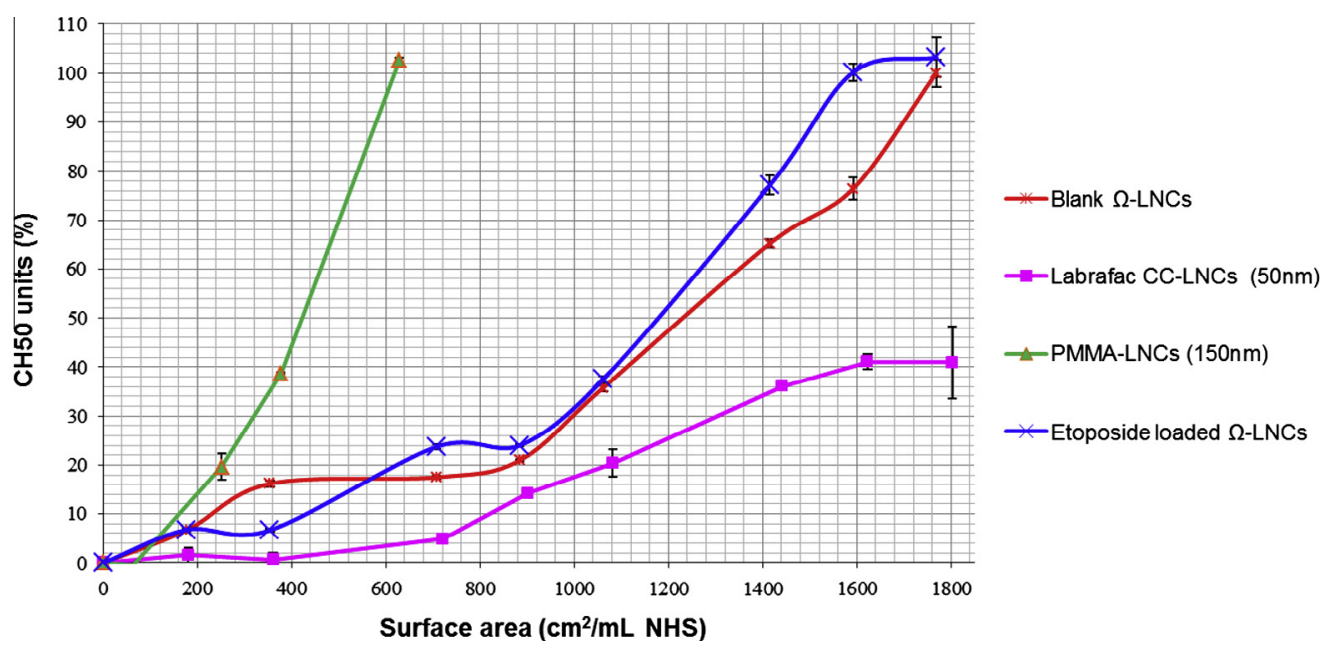

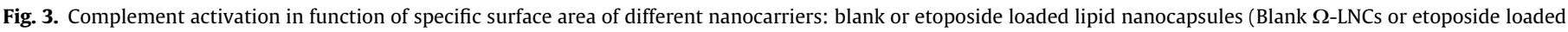
$\Omega$-LNCs) see characteristics in text; Labrafac ${ }^{\circledR}$ CC nanocapsules (Labrafac ${ }^{\circledR}$ CC-LNCs) with a mean size of 50 nm; or PMMA nanoparticles (PMMA-LNCs).

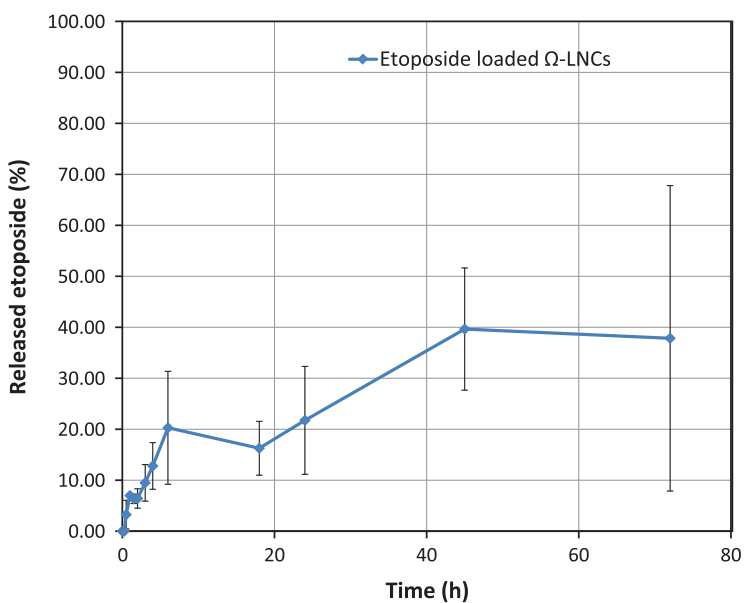

Fig. 4. Release study of etoposide from lipid nanocapsules ( $\Omega$-LNCs) over time in a medium mimicing plasma, $n=3$.

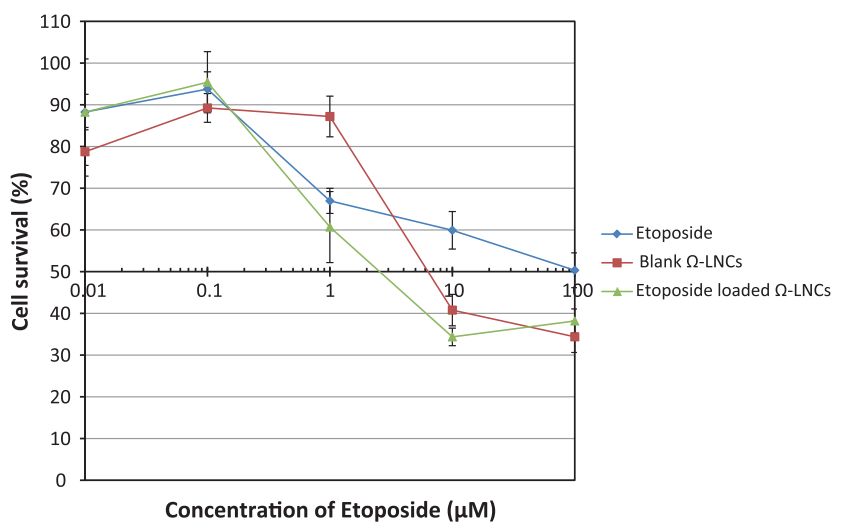

Fig. 5. Cyquant ${ }^{\circledR}$ cell survival assay on $\mathrm{H} 209$ cells after $72 \mathrm{~h}$, relatively to the concentration of etoposide encapsulated or not in lipid nanocapsules ( $\Omega$-LNCs), $n=3$.

resulting in an $\mathrm{IC}_{50}$ of about $2.5 \mu \mathrm{M}$ and $6 \mu \mathrm{M}$, respectively. Moreover, the cytostatic effect of etoposide solution was lower since its IC50 was $100 \mu \mathrm{M}$.

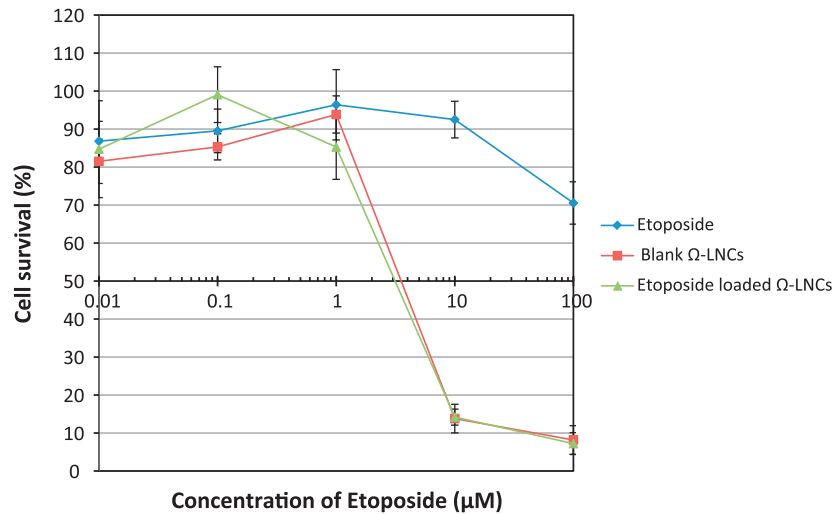

Fig. 6. Cyquant ${ }^{\circledR}$ cell survival assay on H69AR cells after $72 \mathrm{~h}$, relatively to the concentration of etoposide encapsulated or not in lipid nanocapsules ( $\Omega$-LNCs), $n=3$.

Table 6

Characteristics of LNCs obtained with the original $\Omega$-formulation (see text for details) or after a $15 \times$ scale-up.

\begin{tabular}{lcl}
\hline Quantity of materials & $\Omega$-Formulation & \\
\cline { 2 - 3 } & $\begin{array}{l}\text { Initial formulation } \\
(n=3)\end{array}$ & $\begin{array}{l}15 \times \text { Scale-up } \\
(n=1)\end{array}$ \\
\hline Size (nm) & $54.1 \pm 2.0$ & 50.42 \\
Main peak (\%) & $99.9 \pm 0.2$ & 100 \\
Polydispersity index & $0.100 \pm 0.020$ & 0.068 \\
Zeta potential (mV) & $-5.8 \pm 3.5$ & -0.032 \\
Encapsulation efficiency & $75.8 \pm 3.3$ & 80.1 \\
$\quad$ (\%) & $5.7 \pm 0.3$ & 6.0 \\
\hline
\end{tabular}

H69AR cell culture studies confirmed the resistant character of these cells at etoposide solution since a slightly cell survival decrease (over 70\%) was observed at higher concentration $\left(\mathrm{IC}_{50}>100 \mu \mathrm{M}\right)$. On the other hand, blank-LNCs and etoposideLNCs had similar toxicity on H69AR cells. Cell survival was dramatically decreased (below 20\%) at the concentration of $10 \mu \mathrm{M}$, resulting in an $\mathrm{IC}_{50}$ of about $3 \mu \mathrm{M}$ for both blank-LNCs and etoposide-LNCs. 


\subsection{Scale-up}

Finally, a scale-up of the $\Omega$-formulation was performed. The weight of all compounds was multiply by 15 folds. These LNCs were compared to $\Omega$-LNCs, formulated at initial-scale, in terms of their drug loading and morphological characteristics (Table 6). No difference was observed on LNCs characteristics. These results indicate that $\Omega$-LNs can be produced on a larger scale.

\section{Discussion}

One of the major challenges in drug nanoencapsulation consists in obtaining the higher drug loading in a smallest nanocarrier. Polymeric nanoparticles and solid lipid nanoparticles (SLN), which have a broad range of medical applications, were used to encapsulate etoposide. The first ones were formulated with biodegradable polymers such as polylactic acid (PLA) (Gaucher et al., 2007), polylactide-co-glycolic acid (PLGA) (Snehalatha et al., 2008; Yadav et al., 2011), polycaprolactone (PCL) (Snehalatha et al., 2008) or poly(3-hydroxybutyrate-co-3-hydroxyhexanoate) (PHBHHX) (Kilicay et al., 2011) by nanoprecipitation or solvent evaporation techniques. These nanoparticles, whose size is greater than $100 \mathrm{~nm}$, showed drug loading upper than $2 \%(\mathrm{w} / \mathrm{w})$ and encapsulation efficiency up to $80 \%$. The SLN (Reddy et al., 2006) or nanostructured lipid carriers (Patlolla and Vobalaboina, 2008; Zhang et al., 2011) are characterized by an encapsulation efficiency close to $100 \%$ for etoposide and a drug loading upper than $2 \%$ but high temperature $\left(>75^{\circ} \mathrm{C}\right)$ was necessary to obtain nanocarriers. Recently, encapsulation of the anticancer drug etoposide was achieved inside PEGylated poly(propylene imine) dendrimer and it was found that 20-21 molecules of drug are solubilized per dendritic polymer (Sideratou et al., 2010). Encapsulation of etoposide was also performed in polymeric micelles (Mohanty et al., 2010) or fatty acids micelles (Varshosaz et al., 2012). However, all these formulations required organic solvents that can be harmful for the patients.

In response to this problem, PLGA nanoparticles of etoposide were developed using fully biocompatible nanoprecipitation technique (Callewaert et al., 2012). For that, the polymer was dissolved in glycofurol, an injectable solvent. Unfortunately, encapsulation efficiency was dramatically decreased $(<15 \%)$, probably due to the low extraction of the glycofurol by the external phase. Lipid nanospheres were also prepared by dissolving etoposide in oily components without any organic solvents (Patlolla and Vobalaboina, 2008) resulting in a lower drug loading generally observed for this encapsulation technique.

In a previous study performed by our group, etoposide encapsulation was obtained in LNCs, with Labrafac ${ }^{\circledR} \mathrm{CC}$ as oily core, resulting in drug loading close to $2.7 \mathrm{mg} / \mathrm{g}$ dry nanoparticles and encapsulation efficiency up to 90\% (Lamprecht and Benoit, 2006). However, etoposide was dissolved in this neutral oil prior to all the preparation steps, in presence of methanol. Despite those drawbacks, the obtained nanocapsules were very promising because they suppressed glioma cell growth in vitro and displayed P-glycoprotein inhibition. This latter interesting property has since been obtained on other cell lines with LNCs (Roger et al., 2010).

In view of the previous cited studies, there was thus still a need for a biocompatible etoposide nanocarrier, displaying a drug loading that allows therapeutic use of the drug. The aim of this study was to achieve etoposide loaded LNCs without any organic solvents and a higher drug loading. Results of solubility study showed that among oily excipients evaluated, Transcutol ${ }^{\circledR}$ HP was the best candidate to solubilize etoposide. So, an LNC formulation previously developed for Sn38 encapsulation (Roger et al., 2011) has been adapted, in order to obtain etoposide-LNCs formulation with an average size of $50 \mathrm{~nm}$ and a polydispersity index lower than 0.2 .
Upon further optimization with drug loading and polydispersity as main targets, an etoposide-LNCs formulation, called $\Omega$-LNCs, was obtained, which oily core was made of $20 \%$ Transcutol $^{\circledR} \mathrm{HP}$, $60 \%$ Labrafil ${ }^{\circledR}$ M1944CS and 20\% Labrafac $^{\circledR}$ CC. These new LNCs display an average size of $54.1 \pm 0.2 \mathrm{~nm}$ and a low polydispersity index of $0.10 \pm 0.02$. The obtained encapsulation efficiency was approximately $76 \%$ for a drug loading of $6 \mathrm{mg} / \mathrm{g}$ of dry LNCs (etoposide concentration was approximately $12 \mathrm{mg} / \mathrm{g}$ of lipid). Moreover, the present formulation differs from that developed for Sn38 on two main points. Firstly, the addition of Transcutol ${ }^{\circledR}$ HP containing dissolved etoposide, was not performed with all other components before the three heating-cooling cycles, but at the beginning of the last cooling, as described in one of our recent patent (Benoit et al., 2010). The second important improvement on this formulation is that, Lipoïd ${ }^{\circledR}$ S75-3 has been removed of original formulation to obtain what was called the $\Omega$-LNCs formulation. This surfactant, a lecithin, was added initially to the LNCs formulation in order to reinforce the nanocapsule shell but it was difficult to solubilize and could generate an increase of polydispersity index. The stability study of the $\Omega$-LNCs showed that the absence of Lipoïd ${ }^{\circledR}$ S75-3 in the formulation did not alter the LNC characteristics. Moreover, classical LNCs, i.e., with Lipoïd ${ }^{\circledR}$ S75-3, required addition of trehalose as cryoprotectant in order to preserve their monodisperse characteristics (Dulieu and Bazile, 2005). It has been possible to lyophilize the $\Omega$-LNCs, in absence of cryoprotectant, without any change of size and polydispersity index after resuspension. In a precedent study, Vrignaud et al. (2011) observed the ability of their LNCs to bear a freeze-drying process without cryoprotectant, and without important change in their sizes and surface potentials. As $\Omega$-LNCs studied here, these LNCs have been formulated in absence of Lipoïd ${ }^{\circledR}$ S75-3. Moreover, works about freeze-drying of nanoparticles mentioned that PEG could act as stabilizers, and protect the product during freeze-drying against the freezing and the drying stresses (Abdelwahed et al., 2006). Even if Lipoïd ${ }^{\circledR}$ S75-3 is anchored in the oily phase, the shell of the classical LNCs was made from a mixture of Solutol ${ }^{\circledR}$ HS15 and Lipoïd ${ }^{\circledR}$ S75-3. In the LNCs synthesized without Lipoïd ${ }^{\circledR}$ S75-3, the shell is only made of Solutol $^{\circledR}$ HS15 and the PEG chains of this product probably act as cryoprotectant during the freeze-drying process.

After 3 days, the percentage of etoposide released was about $40 \%$ and reached a plateau. The characteristics of the release of etoposide obtained in this study were relatively close to those obtained by Lamprecht and Benoit (2006) with the same drug encapsulated in classical LNCs, i.e., with an oily core only composed of Labrafac ${ }^{\circledR}$ CC. On the other hand, there were very different from those obtained for camptothecin with a formulation of LNCs that was close to the $\Omega$ formulation (Roger et al., 2011). Thus, the first obtained a release of etoposide up to $60 \%$ after $24 \mathrm{~h}$ in a sink media buffered at 7.4 while the second described a release of about $7 \%$ over the same period in a phosphate buffered medium at the same $\mathrm{pH}$ and protein-free in non-sink conditions. These differences can be explained by the solubility profile of Sn38 and etoposide, $\log P=2.65$ and 0.60 respectively and the presence of protein that helps dissolution process in the first study. The fact that our results, obtained in a media close to the one used by Lamprecht and Benoit (2006), are similar to what was obtained by those authors, underline that the drug release process was not affected by our new formulation.

The hemolytic complement activation provided predictive indicators for in vivo long-circulating behavior, according to the stealth properties of the nanoparticles. $\Omega$-LNCs loaded or non-loaded with etoposide showed similar activating properties of the complement suggesting a real encapsulation of the drug. Moreover, a low activation of complement proteins was observed at low surface values (until $1000 \mathrm{~cm}^{2}$ ), similar to that observed for standard $50-\mathrm{nm}$ LNCs, i.e., LNCs whose oily core was only composed of Labrafac ${ }^{\circledR}$ 
CC. In this area, corresponding to less than $20 \%$ of activation, it is recognized that the circulation time in plasma of LNCs would be acceptable for therapeutic treatment. However, this result has to be confirmed with in vivo evaluation, and it will be necessary to test the activity of LNCs loaded with etoposide on animals bearing a previously described tumor-type small cell lung cancer (Iochmann et al., 2012) to determine whether these objects are actually suitable for treatment.

Finally, the results of in vitro cells viability on non-resistant cells H209 showed that the etoposide encapsulation in $\Omega$-LNCs formulation did not compromise its cytostatic effect. At $1 \mu \mathrm{M}$ etoposide concentration, the encapsulated form even led to a slight decrease of the cells viability compared to the etoposide solution, while the blank $\Omega$-LNCs remained without any cytotoxic effect. No effect of etoposide loaded LNCs was observed on H69AR resistant cells. In fact, H69AR cells were obtained after selection in culture with increasing concentration of adriamycin (Mirski et al., 1987). These cells expressed a multidrug resistant phenotype and do not over express p-glycoprotein as many other multiresistant cell lines. Our nanoparticles have been showed to inhibit p-glycoprotein (Garcion et al., 2006), this is another evidence that the resistance of H69AR cells is not linked to p-glycoprotein. The resistance is due to a decrease of susceptibility to drug-induced DNA damage (Cole et al., 1991), this is why the encapsulation in nanocapsules failed to reverse cell resistance to etoposide. Only intrinsic toxicity of blank LNCs was observed for the high concentrations evaluated $(10-100 \mu \mathrm{M})$. Nevertheless, only in vivo experiments could correctly describe therapeutic benefit of $\Omega$-LNCs.

\section{Conclusions}

This study demonstrated the feasibility of etoposide-LNCs and improvements over the original promising formulation developed in our group several years ago.

The new LNCs were formulated without any use of solvents compared to other systems encapsulating etoposide. The LNCs are adapted to the effect of tissue permeability and retention (EPR) because their diameter was close to $50 \mathrm{~nm}$. Finally, even if they have a drug loading less than other systems, they have one of the most important encapsulation efficiency of etoposide ever reached. Adapted to scale-up and freeze drying, containing only GRAS excipients, these new formulations are suitable for industrial process.

The performances of this formulation are promising, and make these LNCs a good nanomedicine candidate for preclinical animal studies in the view to elaborate a new therapeutic treatment of SCLC.

\section{References}

Abdelwahed, W., Degobert, G., Stainmesse, S., Fessi, H., 2006. Freeze-drying of nanoparticles: formulation, process and storage considerations. Adv. Drug Deliv. Rev. 58, 1688-1713.

Beauchesne, P., Bonner, J.A., Mornex, F., Brunon, J., 1999. Sensitivity to etoposide of human malignant glioma cell lines. Mechanisms of action. Cancer Radiother. 3 , $57-64$.

Benoit, J.P., Saulnier, P., Anton, N., 2010. Process for preparing lipid nanoparticles. WO2009004214.

Callewaert, M., Dukic, S., Van Gulick, L., Vittier, M., Gafa, V., Andry, M.C., Molinari, M., Roullin, V.G., 2012. Etoposide encapsulation in surface-modified poly(lactide-co-glycolide) nanoparticles strongly enhances glioma antitumor efficiency. J. Biomed. Mater. Res. A.

Cole, S.P., Chanda, E.R., Dicke, F.P., Gerlach, J.H., Mirski, S.E., 1991. Non-Pglycoprotein-mediated multidrug resistance in a small cell lung cancer cell line: evidence for decreased susceptibility to drug-induced DNA damage and reduced levels of topoisomerase II. Cancer Res. 51, 3345-3352.

Dulieu, C., Bazile, D., 2005. Influence of lipid nanocapsules composition on their aptness to freeze-drying. Pharm. Res. 22, 285-292.
Ellis, A.G., Crinis, N.A., Webster, L.K., 1996. Inhibition of etoposide elimination in the isolated perfused rat liver by Cremophor EL and Tween 80. Cancer Chemother. Pharmacol. 38, 81-87.

Garcion, E., Lamprecht, A., Heurtault, B., Paillard, A., Aubert-Pouessel, A., Denizot, B., Menei, P., Benoit, J.P., 2006. A new generation of anticancer, drug-loaded, colloidal vectors reverses multidrug resistance in glioma and reduces tumor progression in rats. Mol. Cancer. Ther. 5, 1710-1722.

Gaucher, G., Poreba, M., Ravenelle, F., Leroux, J.C., 2007. Poly(N-vinyl-pyrrolidone)block-poly(D,L-lactide) as polymeric emulsifier for the preparation of biodegradable nanoparticles. J. Pharm. Sci. 96, 1763-1775.

Hainsworth, J.D., Greco, F.A., 1995. Etoposide: twenty years later. Ann. Oncol. 6, 325-341.

Heurtault, B., Saulnier, P., Benoit, J.P., Pech, B., Proust, J.E., Richard, J., 2001. Lipid nanocapsules, preparation, process and use as a medicine. WO0164328.

Heurtault, B., Saulnier, P., Pech, B., Proust, J.E., Benoit, J.P., 2002. A novel phase inversion-based process for the preparation of lipid nanocarriers. Pharm. Res. $19,875-880$.

Hillgenberg, M., Schlehofer, J.R., von Knebel Doeberitz, M., Klein-Bauernschmitt, P., 1999. Enhanced sensitivity of small cell lung cancer cell lines to cisplatin and etoposide after infection with adeno-associated virus type 2. Eur. J. Cancer 35 106-110.

Hureaux, J., Lagarce, F., Gagnadoux, F., Clavreul, A., Benoit, J.P., Urban, T., 2009. The adaptation of lipid nanocapsule formulations for blood administration in animals. Int. J. Pharm. 379, 266-269.

Hureaux, J., Lagarce, F., Gagnadoux, F., Rousselet, M.C., Moal, V., Urban, T., Benoit, J.P., 2010. Toxicological study and efficacy of blank and paclitaxelloaded lipid nanocapsules after i.v. administration in mice. Pharm. Res. 27, 421-430.

Huynh, N.T., Roger, E., Lautram, N., Benoit, J.P., Passirani, C., 2010. The rise and rise of stealth nanocarriers for cancer therapy: passive versus active targeting. Nanomedicine (London) 5, 1415-1433.

Iochmann, S., Lerondel, S., Blechet, C., Lavergne, M., Pesnel, S., Sobilo, J., HeuzeVourc'h, N., Le Pape, A., Reverdiau, P., 2012. Monitoring of tumour progression using bioluminescence imaging and computed tomography scanning in a nude mouse orthotopic model of human small cell lung cancer. Lung Cancer 77, 7076.

Jelinek, A., Klocking, H.P., 1998. In vitro toxicity of surfactants in U937 cells: cell membrane integrity and mitochondrial function. Exp. Toxicol. Pathol. 50, 472476.

Jinturkar, K.A., Anish, C., Kumar, M.K., Bagchi, T., Panda, A.K., Misra, A.R., 2012. Liposomal formulations of Etoposide and Docetaxel for p53 mediated enhanced cytotoxicity in lung cancer cell lines. Biomaterials 33, 2492-2507.

Khajavinia, A., Varshosaz, J., Dehkordi, A.J., 2012. Targeting etoposide to acute myelogenous leukaemia cells using nanostructured lipid carriers coated with transferrin. Nanotechnology 23, 405101.

Kilicay, E., Demirbilek, M., Turk, M., Guven, E., Hazer, B., Denkbas, E.B., 2011. Preparation and characterization of poly(3-hydroxybutyrate-co-3hydroxyhexanoate) (PHBHHX) based nanoparticles for targeted cancer therapy. Eur. J. Pharm. Sci. 44, 310-320.

Lamprecht, A., Benoit, J.P., 2006. Etoposide nanocarriers suppress glioma cell growth by intracellular drug delivery and simultaneous P-glycoprotein inhibition. J. Controlled Release 112, 208-213.

Mirski, S.E., Gerlach, J.H., Cole, S.P., 1987. Multidrug resistance in a human small cell lung cancer cell line selected in adriamycin. Cancer Res. 47, 2594-2598.

Mohanty, A.K., Dilnawaz, F., Mohanty, C., Sahoo, S.K., 2010. Etoposide-loaded biodegradable amphiphilic methoxy (poly ethylene glycol) and poly(epsilon caprolactone) copolymeric micelles as drug delivery vehicle for cancer therapy. Drug Deliv. 17, 330-342.

Patlolla, R.R., Vobalaboina, V., 2008. Folate-targeted etoposide-encapsulated lipid nanospheres. J. Drug Target 16, 269-275.

Poreba, R., Gac, P., Poreba, M., Andrzejak, R., 2011. Environmental and occupational exposure to lead as a potential risk factor for cardiovascular disease. Environ. Toxicol. Pharmacol. 31, 267-277.

Reddy, L.H., Adhikari, J.S., Dwarakanath, B.S., Sharma, R.K., Murthy, R.R., 2006. Tumoricidal effects of etoposide incorporated into solid lipid nanoparticles after intraperitoneal administration in Dalton's lymphoma bearing mice. AAPS J. 8, E254-262.

Roger, E., Lagarce, F., Garcion, E., Benoit, J.P., 2010. Reciprocal competition between lipid nanocapsules and P-gp for paclitaxel transport across Caco-2 cells. Eur. J. Pharm. Sci. 40, 422-429.

Roger, E., Lagarce, F., Benoit, J.P., 2011. Development and characterization of a novel lipid nanocapsule formulation of Sn38 for oral administration. Eur. J. Pharm. Biopharm. 79, 181-188.

Shirazi, F.H., Bahrami, G., Stewart, D.J., Tomiak, E., Delorme, F., Noel, D., Goel, R., 2001. A rapid reversed phase high performance liquid chromatographic method for determination of etoposide (VP-16) in human plasma. J. Pharm. Biomed. Anal. 25, 353-356.

Sideratou, Z., Kontoyianni, C., Drossopoulou, G.I., Paleos, C.M., 2010. Synthesis of a folate functionalized PEGylated poly(propylene imine) dendrimer as prospective targeted drug delivery system. Bioorg. Med. Chem. Lett. 20, 6513-6517.

Snehalatha, M., Venugopal, K., Saha, R.N., Babbar, A.K., Sharma, R.K., 2008. Etoposide loaded PLGA and PCL nanoparticles II: biodistribution and pharmacokinetics after radiolabeling with Tc-99m. Drug Deliv. 15, 277-287.

van Meerbeeck, J.P., Fennell, D.A., De Ruysscher, D.K., 2011. Small-cell lung cancer. Lancet 378, 1741-1755. 
Varshosaz, J., Hasanzadeh, F., Eslamdoost, M., 2012. Optimization of self-assembling properties of fatty acids grafted to methoxy poly(ethylene glycol) as nanocarriers for etoposide. Acta Pharm. 62, 31-44.

Vonarbourg, A., Passirani, C., Saulnier, P., Simard, P., Leroux, J.C., Benoit, J.P., 2006. Evaluation of pegylated lipid nanocapsules versus complement system activation and macrophage uptake. J. Biomed. Mater. Res. A 78, 620-628.

Vrignaud, S., Anton, N., Gayet, P., Benoit, J.P., Saulnier, P., 2011. Reverse micelleloaded lipid nanocarriers: a novel drug delivery system for the sustained release of doxorubicin hydrochloride. Eur. J. Pharm. Biopharm. 79, 197-204.
Yadav, K.S., Jacob, S., Sachdeva, G., Sawant, K.K., 2011. Intracellular delivery of etoposide loaded biodegradable nanoparticles: cytotoxicity and cellular uptake studies. J. Nanosci. Nanotechnol. 11, 6657-6667.

You, B., Tranchand, B., Girard, P., Falandry, C., Ribba, B., Chabaud, S., Souquet, P.J., Court-Fortune, I., Trillet-Lenoir, V., Fournel, C. Tod, M. Freyer, G, 2008. Etoposide pharmacokinetics and survival in patients with small cell lung cancer: a multicentre study. Lung Cancer 62, 261-272.

Zhang, T., Chen, J., Zhang, Y., Shen, Q., Pan, W., 2011. Characterization and evaluation of nanostructured lipid carrier as a vehicle for oral delivery of etoposide. Eur. J. Pharm. Sci. 43, 174-179. 